\title{
PREVALENCE AND PREDICTORS OF TOBACCO USE AMONG SCHOOL ADOLESCENTS IN ZAKHO, KURDISTAN REGION OF IRAQ
}

\author{
Hamid S. Kachel ${ }^{\text {a, }}$, Mohammed A. Ageed ${ }^{\text {a }}$, Nergiz H. Omer ${ }^{\text {a }}$, and Mohammed I. Suleiman ${ }^{\text {b }}$

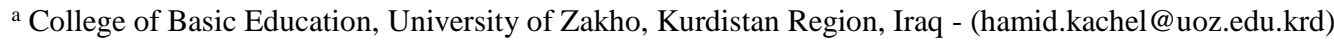 \\ ${ }^{\mathrm{b}}$ Faculty of Education, University of Zakho, Kurdistan Region, Iraq
}

Received: Jul. 2018 / Accepted: Sept., 2018 / Published: Sept., 2018

https://doi.org/10.25271/sjuoz.2018.6.3.503

\begin{abstract}
:
Knowledge regarding smoking prevalence among the Iraqi Kurdistan general population is not clear, at least for males. Here in the Kurdistan Youth Smoking Survey (KYSS) we tried to further expand our knowledge about the smoking profile of school students across Kurdistan Region of Iraq. Five hundred students from four Zakho male schools from grades six to nine participated in the study to determine the prevalence of smoking and socio-demographical factors associating with smoking among students aged 12 to 15 years. The KYSS questionnaire included various parameters such as age, gender, friends, parent history and blood groups. This study showed that the prevalence of students who ever tried smoking was $76 \%$; about $65 \%$ of them started at age 12 years or less. Although the majority of participants (95\%) knew that smoking is harmful and had negative impact on human health, $18 \%$ of them thought that they will never quit smoking. The study concluded that there was slight association between family monthly income, parents' educational level and blood groups with smoking initiation habits. On the other hand, the three most critical factors connected with initiating smoking habits reported by students were age, peer influence and father smoking.
\end{abstract}

KEYWORDS: Prevalence of smoking, Kurdistan Youth Smoking Survey, Socio-demographical factors, Adolescents smoking.

\section{INTRODUCTION}

Smoking is the preventable leading cause of mortality and morbidity in the world (Lopez and Mathers, 2006). According to the 2015 World Health Organization (WHO) report each year smoking kills six million people with ten percentage of deaths as a second hand smoker (WHO, 2014). Death by tobacco use is expected to increase by 2030 to more than eight to ten million people per year with $70-80 \%$ in the developing world countries (Chan, 2008).

The young, 12-17 years (Siziya et al., 2007), and early adult, 18-28 years, ages have been identified as critical periods in the human life for initiating smoking habits. Smoking in the young age might lead them to develop other unhealthy lifestyle behaviours such as engagement in illicit drug and alcohol use (Brook et al., 2007). It has been reported that tobacco related diseases such as hypertension, respiratory diseases, cancer and cardiovascular disease are among the main causes of death and morbidity in Kurdistan (Barzani, 2006).

A few researchers support the idea of association between blood groups and smoking habit. Cohen and Thomas (1962) showed that blood group B is dominated among non-smoker white male, while it was rare between cigarettes heavy smokers. On the other hand, study by Higgins (Higgins et al., 1963) showed that ABO blood group has no any correlation with smoking traits.

In Kurdistan region of Iraq studies focusing on the prevalence and socio-demographical factors associated with smoking habit among school adolescents is limited to Siziya and his colleagues (Siziya et al., 2007). Here in the Kurdistan Youth Smoking Survey (KYSS) we tried to further expand our knowledge about the smoking profile of school students across Kurdistan. Zakho schools were taken as an example to determine the prevalence of smoking and socio-demographical factors associated with smoking among their students.

\section{METHODS}

\subsection{Study design and study sample}

A cross sectional study was conducted among male students in Zakho schools at grades 6, 7, 8 and 9 by random sampling from four public schools with approximately 500 student responses obtained in all schools, and roughly 25-27 students in each class. Two schools in Zakho central and another two in the countryside were chosen randomly among all public male schools to represent social demographic and cultural diversity in Zakho city. Data on class sizes for all schools were obtained from the school manager and this information was used for the distribution of the questionnaire.

\subsection{Questionnaire}

The KYSS questionnaire is a modified version of the Global Youth Tobacco Survey (GYTS) questionnaire, which is available to all countries around the world and developed by WHO in conjunction with other health centers. The GTYS questionnaire is a standard instrument used to assess smoking prevalence and other variables related to smoking in the youth age of 12-15 years (GYTS, 2018).

The validity of the KYSS questionnaire was reviewed by experts in the field of smoking surveys, to ensure that is effectively covered the area of investigation. The questions were written in simple language and clearly explained to participants by the project organiser. Furthermore, teachers were asked to leave the class while the survey was conducted to remove any influence over the answers

The KYSS survey had fifteen questions culturally relevant and more appropriate to the age of the students' population at the city of Zakho. The first few questions were related to personal information on gender, age and blood group. Blood group variable added to this survey as a biological factor due to the

\footnotetext{
* Corresponding author

This is an open access under a CC BY-NC-SA 4.0 license (https://creativecommons.org/licenses/by-nc-sa/4.0/)
} 
critical role of blood in many human disease and habits. The remaining questions dealt with experience, knowledge and opinions towards smoking, exposure to smoking, and attitudes toward stopping smoking.

The questionnaire was distributed to classes $6,7,8$ and 9 chosen randomly by project organizer students. Questions had response categories, which had to be ticked off. Multiple responses to any question were not allowed and participation was voluntary and anonymous.

\section{Data Collection}

The distribution of the questionnaire was handled by students who were hired specifically to administer the questionnaire, give a brief introduction to the survey, collect and collate them and return them to the project coordinator.

\subsection{Data entry and analysis}

The project supervisor and an assistant entered data into the Access database for the creation of queries and reports. A Statistical Package for the Social Sciences (SPSS) was used to analyse the data, which formed the basis of the observations and trends that were highlighted. Chi-square test was used to find any significant relationship between variables. The limitations of the analysis were also discussed and proposed action for follow up was identified.

\section{RESULTS}

A total of 500 male students of the 525 students targeted from four different schools at the city of Zakho participated in the survey. This yielded a response rate of $95.2 \%$. All 500 respondents did not, however, answer all the questions. For the purpose of this paper missing values have been used for missing questions from the respondent populations. Questions have missing value are number of cigarettes took daily and the last question regarding students' thought about smoking. Respondents ranged in age from 12-15 years.

Firstly, Students were asked whether they had ever tried or experimented cigarette smoking, even one or two puffs (Table 1). The results indicated that 382 or $76 \%$ of the respondents answered positively. Among the responses of the students who had experienced smoking, $68 \%$ of them were now daily smokers, roughly four, six and thirteen-fold higher than monthly, weekly and never smoke now, respectively.

The majority of smokers (approximately 86\%) smoke one to ten cigarettes a day. When asked how old they were when they first tried a cigarette, $64.9 \%$ stated that they were 12 years or less when they had their first experience with smoking and 14 $\%$ indicated they were 14 years or older (Table 1 ).

Table 1. Smoking prevalence and initiation among study population.

\begin{tabular}{|l|l|l|}
\hline Questions & Respondent & No. (\%) \\
\hline $\begin{array}{l}\text { Have you ever smoked a } \\
\text { cigarette, even just a few puffs? }\end{array}$ & Yes & $382(76)$ \\
& No & $118(24)$ \\
\hline \multirow{3}{*}{ How often do you smoke now? } & Never & $20(5.2)$ \\
& Daily & $260(68)$ \\
& Weekly & $40(10.5)$ \\
& Monthly & $62(16.3)$ \\
\hline \multirow{3}{*}{$\begin{array}{l}\text { How many cigarettes you took } \\
\text { daily? }\end{array}$} & 1 to 10 & $327(85.6)$ \\
& 11 to 20 & $19(5)$ \\
Which age you start smoking? & Missing & $25(6.5)$ \\
& 12 Years or less & $11(2.8)$ \\
\hline & 13 years & $79(20.9)$ \\
& $\begin{array}{l}\text { abyears or ye } \\
\text { above }\end{array}$ & $55(14.4)$ \\
\hline
\end{tabular}

To identify Socio-demographic factors associated with current cigarette smoking, we have performed analysis on our data. It appears that the most significant factor for initiating tobacco smoking was the influence of a friend. In reference to the question about having a close friend who smokes Table 2, it was found that $47.5 \%$ of non-smoker participants had friends who were also non-smokers and only $6.8 \%$ of them had friends who were mostly of them smokers; while $81.4 \%$ of smoker respondent students had some or most friends who smoke frequently. Overall, some pocket money and family income were slightly associated with smoking.

Parents' history of tobacco smoking was also an important factor for smoking initiation. It was found that $49 \%$ of smoking students who were surveyed had a father who smoked while $38.2 \%$ of non-smokers had a smoking father. Contrastingly, $61 \%$ of non-smoking students had a non-smoker parent and $47.6 \%$ of smokers had a non-smoking parent. Parent education level was not connected strongly with smoking initiation among participants in the survey as shown at the bottom of the Table 2 .

Table 2. Socio-demographic factors associated with smoking.

\begin{tabular}{|c|c|c|c|}
\hline \multirow[b]{2}{*}{ Questions } & \multicolumn{3}{|c|}{ Participant respondent No. (\%) } \\
\hline & & Smoker & $\begin{array}{c}\text { Non- } \\
\text { Smoker }\end{array}$ \\
\hline \multirow{3}{*}{$\begin{array}{l}\text { Does your } \\
\text { close friend } \\
\text { Smoke? }\end{array}$} & Most of them & $113(29.6)$ & $8(6.8)$ \\
\hline & Some of them & $198(51.8)$ & $54(45.8)$ \\
\hline & Non-of them & $71(18.6)$ & $56(47.5)$ \\
\hline \multirow{4}{*}{$\begin{array}{l}\text { What is your } \\
\text { monthly } \\
\text { pocket } \\
\text { money? }\end{array}$} & $1000 \mathrm{D}$ & $233(61)$ & $94(79.7)$ \\
\hline & $<1000-15000 \mathrm{D}$ & $130(34)$ & $23(19.5)$ \\
\hline & $<15000-30000 \mathrm{D}$ & $12(3.2)$ & $0 \quad(0)$ \\
\hline & $<30000 \mathrm{D}$ & $7 \quad(1.8)$ & $1 \quad(0.8)$ \\
\hline \multirow{3}{*}{$\begin{array}{l}\text { How much is } \\
\text { your family } \\
\text { monthly } \\
\text { income? }\end{array}$} & $>600000 \mathrm{D}$ & $75(19.7)$ & $16(13.6)$ \\
\hline & $600000 \mathrm{D}$ & $224(58.6)$ & $83(70.3)$ \\
\hline & $<600000 \mathrm{D}$ & $83(21.7)$ & $19(16.1)$ \\
\hline \multirow{4}{*}{$\begin{array}{l}\text { Does any of } \\
\text { your parent } \\
\text { smoke? }\end{array}$} & Father & 187 (49) & $45(38.2)$ \\
\hline & Mother & $3 \quad(0.8)$ & $1 \quad(0.8)$ \\
\hline & Both & $10(2.6)$ & $0 \quad(0)$ \\
\hline & Non-of them & $182(47.6)$ & 72 (61) \\
\hline \multirow{4}{*}{$\begin{array}{l}\text { Does any of } \\
\text { your parents } \\
\text { have an } \\
\text { educational } \\
\text { degree? }\end{array}$} & Father & $136(35.6)$ & $37(31.4)$ \\
\hline & Mother & $33(8.7)$ & $10 \quad(8.5)$ \\
\hline & Both & $148(38.7)$ & $48(40.7)$ \\
\hline & Non-of them & $65(17)$ & $23(19.5)$ \\
\hline
\end{tabular}

Information regarding correlation between $\mathrm{ABO}$ blood groups and smoking is limited. In this survey the frequency of the blood group $\mathrm{B}$ and $\mathrm{AB}$ among non-smoker were slightly above the average of the smoker group, in contrast to the blood group A and $\mathrm{O}$ (Fig. 1), but the difference by using Chi-square test

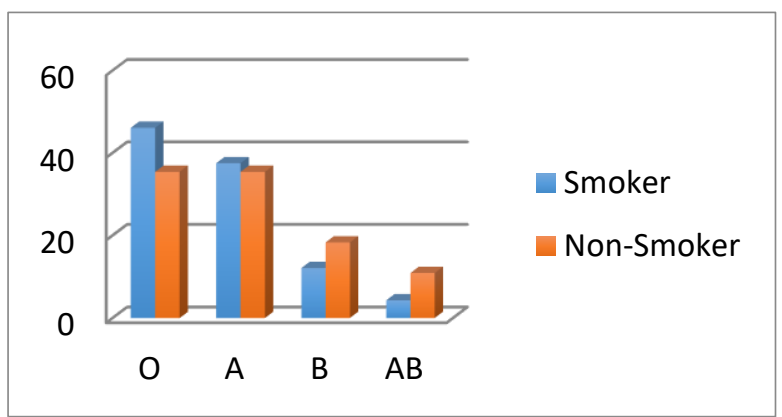

was slightly significant $(\mathrm{p}=0.043)$.

Figure 1. Relationship between blood groups and cigarette smoking.

In response to the question whether they knew smoking was harmful to their health (Fig. 2), in general the majority of respondents $(95 \%)$ believed that smoking definitely had a 
negative effect on their health. The general response from the sample population suggested that $40 \%$ obtained information regarding the harmful effects of smoking from media and 6\%, $7 \%$ and $47 \%$ from newspaper, school and other source, respectively (Fig. 3). Student's opinions regarding the last question, whether they ever thought about stopping smoking, revealed that about $74 \%$ of respondents indicated that they thought seriously about it, while only $18 \%$ indicated an intention to continue smoking (Fig. 4).

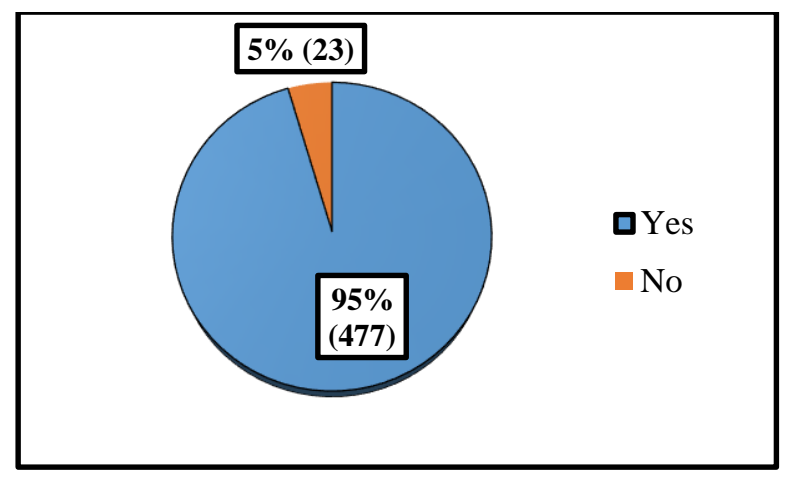

Figure 2. Awareness of smoking impact on health.

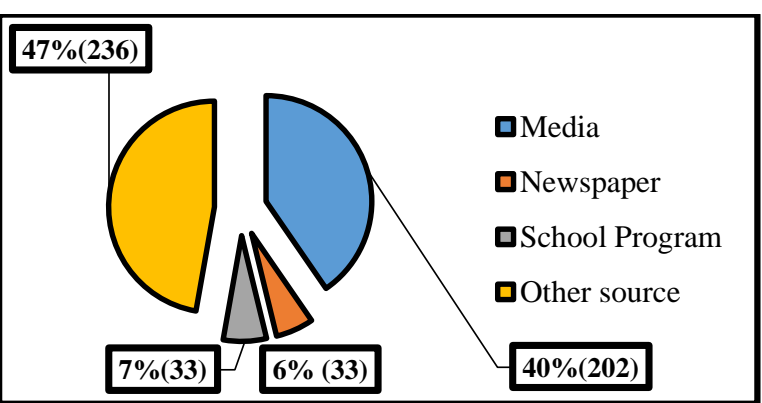

Figure 3. Source of information regarding harmfulness of smoking

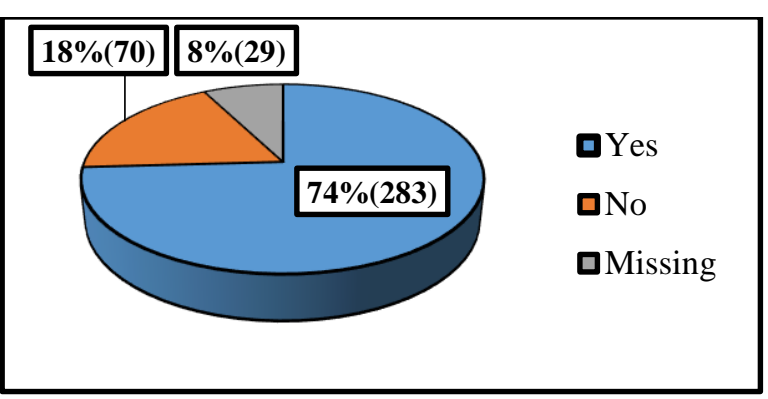

Figure 4. Student s' thoughts regarding quitting smoking

\section{DISCUSSION}

According to the best of our knowledge, this is the first survey investigating in detail the prevalence and Socio-demographic factors related to smoking among school adolescents in the city of Zakho and one of limited studies across the whole of Kurdistan in Iraq. The prevalence of participants who had ever tried cigarettes was $76 \%$. This prevalence is 4.8 -fold higher than previously reported by the Kurdistan Iraq Global Youth Tobacco Survey among boys in 2007 (Siziya et al., 2007). In addition, international studies from neighbouring countries like Syria (Aras et al., 2004) and Turkey (Aras et al., 2007) showed that roughly $30 \%$ of current smokers were 17-21 years of age. The variation between these studies might be due to the difference in the way sample data were collected, analysed and the definition of a smoker.

The two major factors related to the smoking habits are the rate and number of cigarettes smoked per day. Our survey presented that roughly $2 / 3$ of participants confirmed smoking daily; this rate is two-fold higher than the rate reported among Polish students in 2011 (Wojtyła-Buciora et al., 2017). This increase in smoking in adolescence might be due to the weak application of a law in Kurdistan forbidding the sale of cigarettes to those under age 18 as found in other developed countries. Kurdistan Youth Smoking Survey demonstrated that $85 \%$ of students reported that they smoke between one to ten cigarettes daily. In Kurdistan, tobacco use is widely practiced, particularly among adults and older people, as this might be due living in hard environmental conditions and stress of life. In agreement with the idea that culture plays a critical role in determining the adolescent and young adult behaviours, these groups might be at the most vulnerable age period for initiation of smoking (Barzani, 2006). Our study supports that age is an important factor associated with the initiation of smoking. It was clear from the World Health Organization of global tobacco survey report in 2009 that the majority of the students had their first experience of smoking at an early age, usually beginning in their high school years (GATS, 2009). Most of the participants in our survey started their first tobacco smoking at the age of 12 years or less. The key reasons behind smoking initiation at an early age by males are to make impression, curiosity and the need of friend acceptance (Wojtyła-Buciora et al., 2017). The results of our study are identical to that reported earlier by the World Health Organization (Aras et al., 2004).

The influence of friends was found to be strongly associated with the initiation of smoking. It is interesting to note that $47.5 \%$ of non-smoker students had friends who never smoked, while $29.6 \%$ of smokers had friends who were also smokers. Our result is consistent with findings from other studies conducted from other geographical regions with different Socio-demographic culture (Unger et al., 2002). Parent's history also has an influence on tobacco smoking but so less than peer influence. The findings of our survey support a previous study (O'Rourke and Wilson-Davis, 1970) that showed males are more likely to smoke when their father smokes and non-smoker boys mostly have non-smoker parents. Studies investigating the relationship between smoking and human blood group are limited. The finding of our study is in agreement with Cohen and his colleagues (Cohen and Thomas, 1962) who proposed that a correlation between blood group B and smoking habits might exist. Also our data, to a certain degree, is in agreement with a study by Higgins (Higgins et al., 1963) who showed no correlation between ABO blood group and smoking habits. A slight variation among different $\mathrm{ABO}$ blood group frequencies between smokers and non-smokers might be due to the impact of sampling size. Investigation into such an association between blood group and smoking is very important because it might clarify the role of genetic elements in adaptation to different smoking habits.

Overall, the majority of student respondents in this survey (95\%) believe that smoking has a negative impact on health and also has a strong link with many diseases. We found that media $(40 \%)$ and other sources (47\%) like internet are among the main sources of knowledge regard the harmful effects of smoking. Although Kurdistan has a good law with regard to banning smoking advertising on media, nowadays the majority of people have satellite televisions and have access to channels from abroad where most of these countries are still showing tobacco advertising (Barzani, 2006). School program was also among the sources of knowledge with regard to the impact of smoking on health, but this was very low (7\%). The finding in our study that $74 \%$ of respondents wanted to quit smoking in future and $8 \%$ missing value has been reported in this question and $2.8 \%$ for the question related to the number of cigarettes per day. This might be due to any possible reason such as lack of knowledge regarding the question or not -reporting their real behaviour. 


\section{CONCLUSION}

This study showed that there was a slight association between family monthly income, parent education level and blood groups. On the other hand, the three most critical factors connected with smoking initiation habit reported by students were age, peer influence and father smoking. The data from this survey indicated the lack of a teaching program focusing on the effect of smoking on human health. Therefore, we suggest an urgent need for a serious tobacco control program over the whole of Kurdistan region starting with an educational programme from Kindergarten and primary schools and a strong law application to organize the government strategies for reducing tobacco use among the Kurdish population. A finding of our study that $3 / 4$ of respondents wanted to quit smoking in future but do not know how to, suggests that the program mentioned above might be necessary to help them to quit smoking and to start a new healthy life.

\section{REFERENCES}

Aras S., Maziak W., Hammal F., Rastam S., Asfar T.,Eissenberg T., Bachir M., and Fouad M., Ward K.( 2004). Characteristics of cigarette smoking and quitting among university students in Syria. Preventive medicine, 39(2):330- 336.

Aras S., Semin S., Gunay T., Orcin E., and Ozan S. (2007). Sexual attitudes and risk-taking behaviors of high school students in Turkey. The Journal of school health, 77(7):359-366.

Barzani D. (2006). Iraq: an important start in the Kurdish region.Tobacco control, 3-4.

Brook J., Balka E., Ning Y., and Brook D. (2007). Trajectories of cigarette smoking among African Americans and Puerto Ricans from adolescence to young adulthood: associations with dependence on alcohol and illegal drugs. The American Journal on Addictions, 16(3):195-201.

Chan M. (2008). World Health Organization First report on global tobacco use \& control efforts; WHO EMRO Tobacco Free Initiative; 342.
Cohen BH., and Thomas CB. (1962). Comparison of smokers and nonsmokers. II. The distribution of $\mathrm{ABO}$ and $\mathrm{Rh}$ (D) blood groups. Bulletin of the Johns Hopkins Hospita, 110:1-7.

GATS. (2009). Global adult tobacco survey (GATS): Bangladesh. World Health Organization. Available at: http://www.who.int/tobacco/surveillance/fact_sheet_of_ga ts_bangladesh_2009.

GYTS. (2018) Global Youth Tobacco Survey (GYTS): World Health Organization. Available at: https://www.paho.org/hq/index.php?option=com_content $\&$ view $=$ article $\& i d=13432 \&$ Itemid $=40610 \&$ lang $=e s$

Higgins IT., Drummond RJ., Oldham PD., and Bevan B. (1963). Tobacco Smoking and Blood Group. British medical journal, 9; 2(5366): 1167-1169.

Lopez A., and Mathers C. (2006). Measuring the global burden of disease and epidemiological transitions: 2002-2030. Ann Trop Med Parasitol, 100(5-6):481-499.

O'Rourke A., and Wilson-Davis K.. (1970). Smoking and school children. Journal Royal College of General Practitioners, 20(101): 354-360.

Siziya S., Muula A., and Rudatsikira E. (2007). Correlates of current cigarette smoking among in-school adolescents in the Kurdistan region of Iraq. Conflict and health, 1-13.

Unger JB., Yan L., Shakib S., Rohrbach LA., Chen X., Qian G., Chou CP., Jianguo S., Azen S., Zheng H., and Johnson CA. (2002). Peer influences and access to cigarettes as correlates of adolescent smoking: a cross-cultural comparison of Wuhan, China, and California. Preventive medicine, 34(4):476-84.

WHO. "Tobacco Fact sheet N³39" (2014, Retrieved 9 March 2018). Available at : http://www.who.int/en/news-room/factsheets/detail/tobacco.

Wojtyła-Buciora P., Stawińska-Witoszyńska B., Żukiewicz-Sobczak W., Wojtyła C., Biliński P., Urbaniak M., Wojtyła A., Marcinkowski J., and Wojciechowska M. (2017). Trends in smoking among secondary school and high school students in Poland, 2009 and 2011. International journal of occupational medicine and environmental health, 30(5):763-773. 